\title{
Fabrication Techniques of Metal Matrix Composites for Engineering Applications
}

\author{
S. Suresh Kumar, M. Uthayakumar, S. Thirumalai Kumaran, Temel Varol, Fatih Erdemir
}

\begin{abstract}
Metal Matrix Composites (MMCs) are produced by the combinations of two more materials which exhibit better properties than obtained from single. Due to these enhanced properties, it is well suitable in many engineering applications namely aerospace, automobile and structural areas. However processing of MMCs and their properties are depends on the types of fabrication methods employed. This paper aims to discuss about the research work done on synthesis of MMCs through various processing routes. The mechanism of various techniques, the process involved and the parameter selection for each technique were reported. The comparison of fabrication techniques based on different particulars also discussed.
\end{abstract}

Keywords : MMC, fabrication, application.

\section{INTRODUCTION}

The selection of right techniques for fabricating metal matrix composite for high performance engineering application is still challengeable job. Many researchers have reported the significance of different processing methods which suits for various applications. The common processing methods are categorized as follows;

- Liquid state fabrication process

- Solid state fabrication process

- Deposition techniques

- In situ processes.

- Two phase (solid-liquid) processes.

Based on the many factors the selection of process needs to be carried out. However, the researchers have reported the fabrication methods been used for producing MMCs during the last decade and which is shown in Figure 1 [1].

\section{FABRICATION TECHNIQUES}

\section{A. Liquid state fabrication process}

The molten matrix and reinforcements are formed together by solidification mechanism. The following are the various

Revised Manuscript Received on December 5, 2019

S. Suresh Kumar*, Faculty of Mechanical Engineering, Kalasalingam Academy of Research and Education, Srivilliputhur, India. Email: sureshme48@gmail.com

M. Uthayakumar, Faculty of Mechanical Engineering, Kalasalingam Academy of Research and Education, Srivilliputhur, India. Email: uthaykumar@gmail.com

S. Thirumalai Kumaran, Faculty of Mechanical Engineering, Kalasalingam Academy of Research and Education, Srivilliputhur, India. Email: thirumalaikumaran@yahoo.com

Temel Varol, Department of Metallurgical and Materials Engineering, Karadeniz Technical University, Trabzon, Turkey. Email: tvarol@ktu.edu.tr

Fatih Erdemir, Department of Metallurgical and Materials Engineering, Karadeniz Technical University, Trabzon, Turkey. Email: ferdemir@ktu.edu.tr processing methods which come under liquid state fabrication techniques.

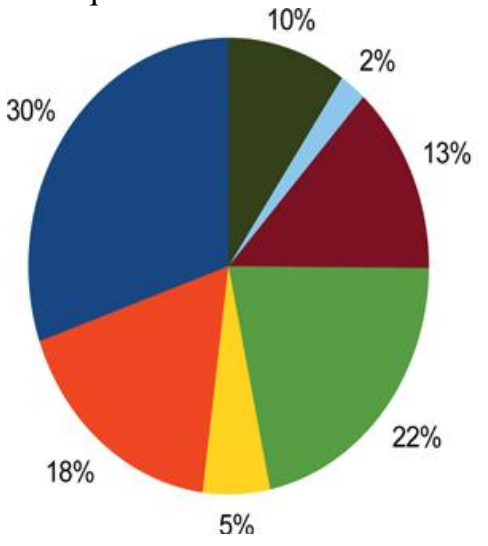

- Powder Metalurgy

- Stir casting

Hot Isostatic Pressing

n Squeeze Casting

- Spray Deposition

Electroplating

- Physical Vapour Deposition

Utilization of various fabrication methods reported in the last decade [1].

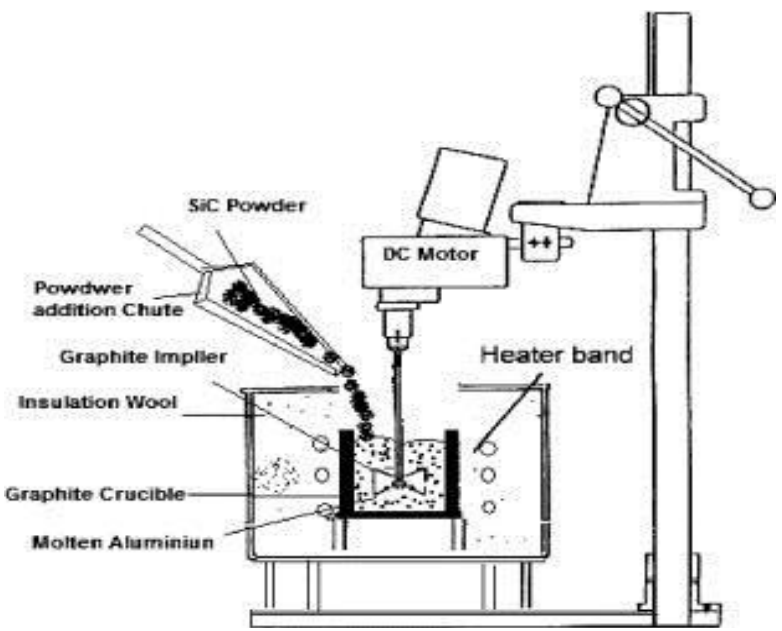

Stir casting process [2]

1) Stir casting process

One of the liquid phase techniques and suitable for fabricating MMCs, in which a reinforcement of ceramic particulates or short fibers are mixed with a molten state of metal by mechanical stirring. The experimental setup of stir casting process is shown in Figure 2.

This process is simple and inexpensive method among liquid phase fabrication. The liquid state of this composite material is cast by suitable casting process.

2) Squeeze casting

It is the forced infiltration process in which molten metal is forced into performed dispersed phase of reinforcements. 
Molten metal is forced by the ram movement into performs which is placed in the lower part of the mould as shown in Figure 3 [3]. The components fabricated through this process are having better dimensional accuracy, higher weldability and high degree of surface finish [4].

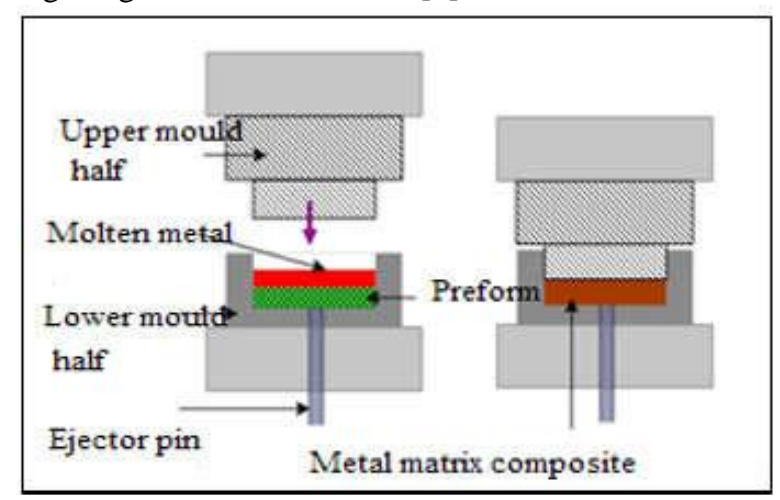

Squeeze casting setup [5]

\section{3) Centrifugal casting process}

Another technique that suits for fabricating functionally graded materials is Centrifugal casting process. It is mostly used for producing cylinders having thin-wall section. With the help of centripetal force, it distributes the liquid state of metal into the cavity mold. The molten metal moves centrifugally towards the wall due to the centripetal force and then solidified after cooling. The fluid flow is the significant parameter and which needs to be well understood, in order to minimize the defects. Many research work was carried out which comprises numerical simulation and experimental part [6]. Figure 4 shows the setup of the centrifugal casting process.

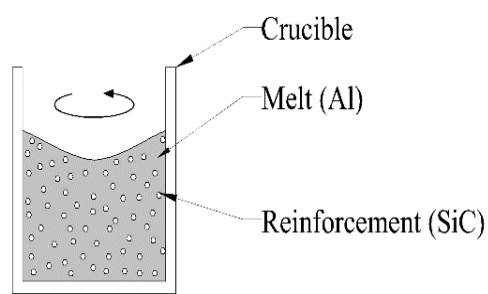

a)

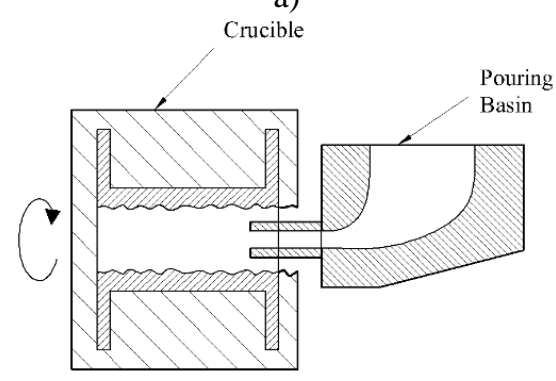

b)

a) Principle of centrifugal casting b) casting setup [7]

Few research works were reported that the particle size and speed are the factor which determines the quality characteristics of casting process. A high swirling is been created by better centripetal force caused by higher rotational speed in the molten liquid puddle [8].

\section{B. SOLID STATE FABRICATION PROCESS}

In case of solid state fabrication process, bonding is induced between matrix material and dispersed phase because of communal diffusion taking place between them in solid phase. In this section, the various solid phase fabrication methods suits for MMCs production are discussed.

1) Powder Metallurgy (PM)

PM process applied extensively for the fabrication of composite with aluminum alloys matrix [9] copper matrices [10-12] and magnesium alloys matrix [13]. A powder metallurgy technique involves the following stages:

- Sieving of particles,

- Blending

- Compressing the mixture,

- Degassing and final consolidation

It is also suitable for different reinforcement such as continuous, non-continuous, particles, platelets. However, $\mathrm{PM}$ is applicable for producing a small objects especially circular cross section. The schematic representation of the various stages of powder metallurgy process is shown in Figure 5.

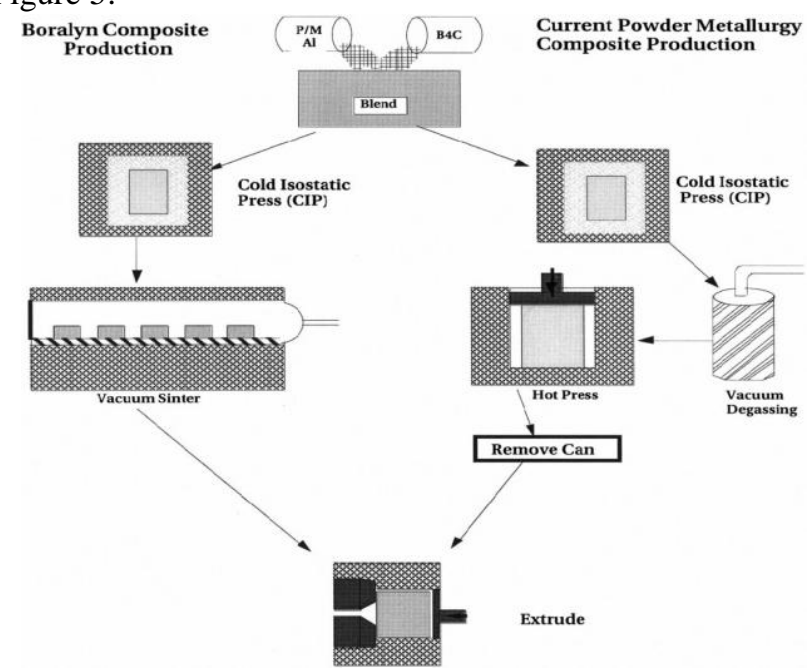

Steps involved for producing PM components [14]

2) High Energy Ball milling
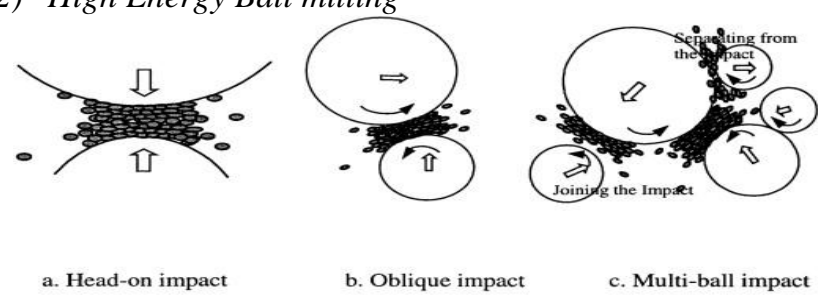

High energy Ball milling- Different impacts

c. Multi-ball impact

Ball milling process makes use of high energy collision from balls to continually forge powder particles together. The various kinds of impact exhibits in the ball milling process are as shown in Figure 6. During milling process, the inclusion of hard particles to the metal alloys enhances the hardness, wear resistance and strength of the composite [15].

The particle distribution, microstructure and fraction influence more the mechanical properties of the composites [16]. 


\section{3) Diffusion Bonding}

Diffusion bonding process comes under solid phase fabrication technique and it is commonly applicable for producing mono filament reinforced aluminium based composite materials. A metallic surface in contact with high temperature exhibits bonding owing to their internal diffusion of atoms between the metal and reinforcement surfaces [18]. Figure 7 shows the process of diffusion bonding induced between metals and fibres.

Pressure

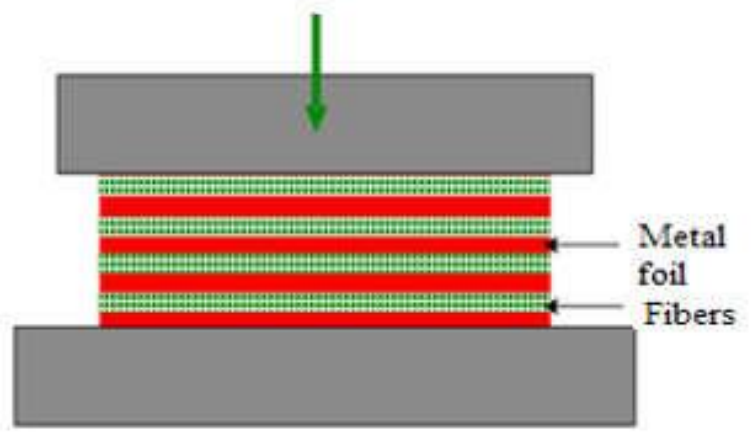

Diffusion bonding process [5]

\section{DEPOSITION TECHNIQUES}

\section{1) Spray forming}

In this method of fabrication, metal/alloy is heated to a molten state in the furnace and forced to flow through an orifice of smaller cross section by the support of compressed inert gas. Simultaneously, the reinforcements were injected through jet and allowed it to break the molten metal into very fine semisolid particles. Then it will be settled down in the substrate provided in order to produce perform of solid phase. Though it is easy and inexpensive process for fabricating MMCs but very tedious to end up with even dispersion of reinforcements in the matrix [19]. The spray forming process is shown in Figure 8.

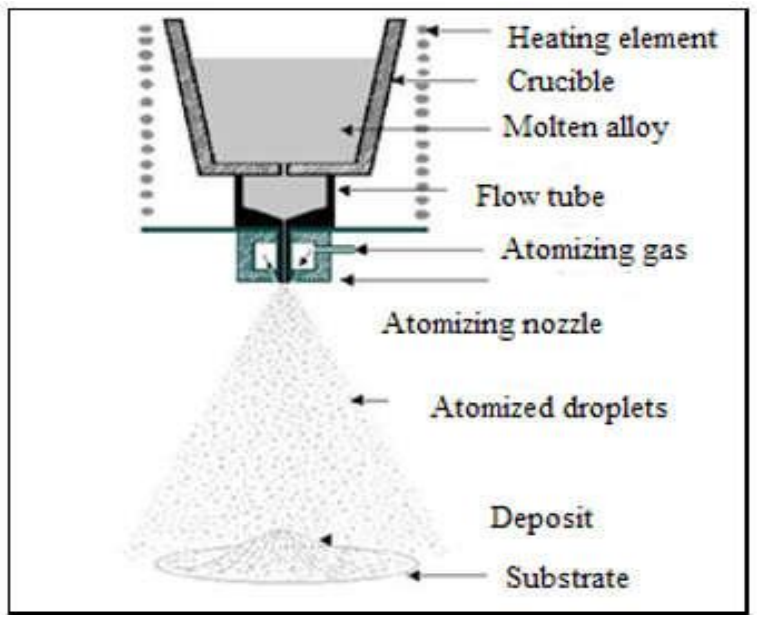

Spray forming process [5]

2) Spray Deposition

In this type of fabrication technique, molten metal is sprayed over the fibers wound on the foil coated drum to form a composite material.

\section{3) Chemical vapor deposition (CVD)}

At the high temperature, a vaporized section decomposes or reacts with one more vaporized chemical which is kept on the substrate to shape a coating on the substrate.

\section{IN SITU FABRICATION OF METAL MATRIX COMPOSITES}

In this process, a reinforcement phase is exhibited in the matrix phase as a outcome of of precipitation from the melt while it cools and Solidifies.

\section{E. TWO PHASE PROCESS}

Two phase process is like a spray deposition method but it involves the mixing of both matrix and reinforcement. Some of the two phase processes suitable for fabricating metal matrix composites are rhea- casting, Osprey.

\section{COMPARISON OF VARIOUS FABRICATION METHODS OF MMCS}

Rodriguez et al. [20] and Sato et al. [21] have done an investigation and reported the significance of stir casting route. It requires low cost for making experimental setup, quick and easy to process and also applicable for mass production which prevents the reinforcement from damage. Table 1 and Table 2 present the collective information on fabrication techniques in the aspect of their application and cost effectiveness process for both liquid and solid phase respectively.

Table- I: LIQUID PHASE FABRICATION - COMPARISON [22-24]

\begin{tabular}{|c|c|c|c|}
\hline $\begin{array}{c}\text { Fabrication } \\
\text { technique }\end{array}$ & $\begin{array}{c}\text { Cost } \\
\text { effectiveness }\end{array}$ & Application & Comments \\
\hline Stir casting & $\begin{array}{c}\text { Least } \\
\text { expensive }\end{array}$ & $\begin{array}{lr}\text { Suitable for mass } \\
\text { production rate. } \\
\text { Mostly applicable } \\
\text { for Al based } \\
\text { composites. } \\
\end{array}$ & $\begin{array}{l}\text { It is } \\
\text { appropriate for } \\
\text { particle } \\
\text { reinforced } \\
\text { AMMC. }\end{array}$ \\
\hline Squeeze casting & medium & $\begin{array}{l}\text { This technique is } \\
\text { applied in } \\
\text { automobile } \\
\text { component } \\
\text { producing industries } \\
\text { such as cylinder } \\
\text { heads, pistons, } \\
\text { rocker arms, } \\
\text { connecting rods }\end{array}$ & $\begin{array}{l}\text { Suitable for } \\
\text { any kind of } \\
\text { reinforcement }\end{array}$ \\
\hline Compocasting & Low & $\begin{array}{l}\text { Mostly applicable in } \\
\text { aerospace and } \\
\text { automobile fields }\end{array}$ & $\begin{array}{l}\text { Applicable for } \\
\text { discontinuous } \\
\text { fibres }\end{array}$ \\
\hline $\begin{array}{l}\text { In-situ } \\
\text { (reactive) } \\
\text { processing }\end{array}$ & Expensive & Automotive & $\begin{array}{l}\text { Uniform } \\
\text { dispersion of } \\
\text { the } \\
\text { reinforcements }\end{array}$ \\
\hline Spray casting & medium & $\begin{array}{l}\text { Used to form cutting } \\
\text { and grinding tools, } \\
\text { electrical brushes } \\
\text { and contacts }\end{array}$ & $\begin{array}{l}\text { Particles } \\
\text { reinforced } \\
\text { components. }\end{array}$ \\
\hline
\end{tabular}

The consolidated details are provided in the above mentioned Table 1 and Table 2. The common problem occurs during the composite fabrication is uniformity of ceramic particles distribution in the matrix phase. 
In order to obtain an excellent property of composite materials, then reinforcement particulates must be dispersed evenly in the matrix materials of ductile nature and also in the interface of matrix and particles.

On the other hand, the fabrication technique available as of now almost produces the agglomerated particles in the matrix and which leads to reduction in ductility nature of the composites [25-26]. The reduction in ductile nature, incapable of producing complex shape at minimum cost, chemical reaction at matrix and particle interface obstructs the implementation of MMCs for engineering requirements. Agglomeration of particles exhibits the brittle nature of MMC and specifically agglomeration is high if the particle sizes are in micro scale or nano scale. Such uneven dispersion of particles form strain gradients locally and lowers the strength of the composites in notable quantity [27]. Moreover, agglomeration behaviour of nano particles, have hindered the fabrication of composite for high performance applications through liquid processing techniques. As well as the uneven distribution of particles in the matrix, these fabrication techniques are not cost-effective. An increase in the processing steps assists the chemical reaction between particulates and matrix at higher temperatures, which leads to secondary brittle phases [28]. Sedat Ozdenet al. [29] have analyzed the impact strength $\mathrm{SiC}$ reinforced $\mathrm{Al}$ matrix composite at various temperatures. The clustering of ceramic particles, poor bonding between matrix and reinforcement affects the impact strength of the composite material. In addition, the influence of clustering nature of particle in the flow behaviour of Aluminium matrix reinforced with $\mathrm{SiC}$ composite were investigated by Zhang Peng et al. [30]. The experimental findings reveal that the clustering of particle has significant influence on tensile deformation behavior and it leads to particle fracture. During the fabrication of $10 \% \mathrm{SiC}$ reinforced $\mathrm{Al}$ matrix composite through stir casting process, the effect of stirring time and speed on particle dispersion were studied by Balasivanandha Prabhuet et al. [31]. The findings of this research work reveal that the cluster formation is high at lower stirring time and speed and also it has an effect on their properties of the composite. Hence, a suitable alternative fabrication technique is required for minimizing the agglomeration behaviour of reinforcement with minimum production time. In order to overcome this shortfall, Hari Babu et al. [32] and Tzamtzis et al. [33] have suggested a new fabrication technique called rheo-process with an intention to form uniformly dispersed particles and also avoiding the formation of agglomeration in the matrix. This process is been carried out by intensive shearing of melt having particles as a cluster. The composite having a fine and uniformly dispersed reinforcement particles obtained from the rheo-processed MMCs enhances the ductile nature and tensile strength simultaneously [34].

Park et al. [35] have studied the influence of addition of $\mathrm{A} 12 \mathrm{O} 3$ in varying fraction with Aluminium matrix. The experimental results revealed that the reduction in fracture toughness was observed with increased $\mathrm{A} 12 \mathrm{O} 3$ content owing to the nucleation of micro scale voids. Kok [36] investigated the mechanical properties of $\mathrm{Al} 2 \mathrm{O} 3$ reinforced $\mathrm{Al}$ alloy based metal matrix composites prepared through vortex method. The findings reported that the optimum conditions to obtain enhanced properties of the composites are stirring speed at $900 \mathrm{rpm}$; preheat temperature of $550 \mathrm{oC}$ and pouring temperature of $700 \mathrm{oC}$ and pressure of $6 \mathrm{MPa}$. The electromagnetic stirring process forms a smaller grain size with improved interface bonding which results in enhanced tensile strength and hardness of the alumina reinforced Aluminium alloy based composites [37]. The suitable method of fabrication for strengthening the matrix and reinforcement bonding is required. It is also an important to taken into account of nature of reinforcement, matrix and reinforcement bonding and wettability behaviour while selecting the reinforcement for the applications.

Table- II: SOLID PHASE FABRICATION - COMPARISON [22-24]

\begin{tabular}{|c|c|c|c|}
\hline $\begin{array}{c}\text { Fabrication } \\
\text { technique }\end{array}$ & $\begin{array}{c}\text { Cost } \\
\text { effectiveness }\end{array}$ & Application & Comments \\
\hline $\begin{array}{l}\text { Powder } \\
\text { metallurgy }\end{array}$ & Medium & $\begin{array}{l}\text { To produce small } \\
\text { circular objects } \\
\text { such as pistons, } \\
\text { bolts and valves. }\end{array}$ & $\begin{array}{l}\text { Though it is suitable } \\
\text { for all reinforcement } \\
\text { and matrix, } \\
\text { excellent for } \\
\text { particle; It exhibits } \\
\text { high } \\
\text { composite. }\end{array}$ \\
\hline $\begin{array}{l}\text { Diffusion } \\
\text { bonding }\end{array}$ & High & $\begin{array}{l}\text { To produce } \\
\text { blades, sheets, } \\
\text { and } \quad \text { structural } \\
\text { components. }\end{array}$ & $\begin{array}{l}\text { Matrix in the form } \\
\text { of sheets and } \\
\text { reinforcements in } \\
\text { the form of } \\
\text { filaments. }\end{array}$ \\
\hline $\begin{array}{l}\text { Ultrasonic } \\
\text { assisted } \\
\text { casting }\end{array}$ & Expensive & $\begin{array}{l}\text { Complex } \\
\text { structural } \\
\text { components and } \\
\text { mass production. }\end{array}$ & $\begin{array}{l}\text { It exhibits almost } \\
\text { homogeneous } \\
\text { dispersion }\end{array}$ \\
\hline
\end{tabular}

\section{CONCLUSIONS}

The fabrication of MMC through various routes is reported here. Based on the nature of the application and materials the technique was selected. The following conclusions were drawn from the literatures reported here.

1) Stir casting is the suggested techniques among liquid state fabrication methods for mass production as it is simple and inexpensive compared to other techniques.

2) Powder metallurgy route can produce small circular composite products at least expensive rate.

3) The particle agglomeration plays major role in the selection of fabrication techniques. The poor selection leads to failure of MMCs.

4) The desired quality of MMC is achieved with the utmost care spent for the selection of fabrication techniques for the different nature of reinforcements.

\section{REFERENCES}

1. Preetkanwal Singh Bains, Sarabjeet Singh Sidhu \& H. S. Payal (2016) Fabrication and Machining of Metal Matrix Composites: A Review, Materials and Manufacturing Processes, 31:5, 553-573.

2. G. Ramu, Ranjit Bauri, 'Effect of equal channel angular pressing (ECAP) on microstructure and properties of $\mathrm{Al}-\mathrm{SiCp}$ composites', Materials \& Design,2009,Vol. 30, Issue 9, pp. 3554-3559.

3. M.R. Ghomashchi, A. Vikhrov, "Squeeze casting: an overview" Journal of Materials Processing Technology 101, 1-9 (2000). 
4. Satish Kumar Thandalam Subramanian Ramanathan, Shalini Sundarrajan, Synthesis, microstructural and mechanical properties of ex situ zircon particles ( $\mathrm{ZrSiO} 4)$ reinforced Metal Matrix Composites (MMCs): a review, j mater res technol. 2015;4(3):333-347.

5. Juhi Mishra, Tejeet Singh, Fabrication of Metal Matrix Composites: A Review, International Journal of Current Research Vol. 9, 59180-59185, 2017.

6. Ebisu Y, Computer simulation on Macrostructure in Centrifugal Castings, AFS Transactions, 1977, 643-655

7. Sijo M T, K R Jayadevan, numerical simulation of centrifugal Casting for functionally graded Metal-matrix composites, International Journal of Mechanical Engineering and Technology, 8, 2017, 66-74.

8. Madhusudhan, Narendranath S, and G C Mohan Kumar, Properties of Centrifugal Casting at Different Rotational Speeds of the Die International Journal of Emerging Technology and Advanced Engineering, Volume 3, Issue 1, 2013, 727-731.

9. Kaczmar, J.W. 1992. K.U. Kainer, Effect of alumina content on properties of PM 6061 aluminium alloys based composite materials, Powder Metall. 35 133-135.

10. Han, B.Q., 1996. K.C. Chan, Superplastic deformation mechanisms of particulate reinforced aluminium alloy matrix composites, Mater. Sci. Eng. 212, 256-264.

11. Kaczmar, J.W., 1989. Effect of production engineering parameters on structure and properties of $\mathrm{Cu}-\mathrm{W}$ composite powders, Powder Metall. 32, 171-175

12. Warrier, K.G.K., Rohatgi, P.K.1984. Copper-titanium electrical contacts, Powder Metall. 29, 65-69.

13. Kehler, H., R. Bode, H. 1995. Haddenhorst, PartikelverstaÈrkte Leichtmetalle, Metal 49, 191-195.

14. Harrigan Jr, W.C. Commercial processing of metal matrix composites Materials Science and Engineering: A 1998, 244 (1), 75-79.

15. G. M. Scamans, N. Birbilis, R. G. Buchheit, "Corrosion of aluminum and its alloys" In Shreir's Corrosion, 3,p.1974 (2010).

16. Y. Saberi, S.M. Zebarjad, G.H. Akbari, On the role of nano-size SiC on lattice strain and grain size of $\mathrm{Al} / \mathrm{SiC}$ nanocomposite ,Journal of Alloys and Compounds 484 (2009) 637-640.

17. D.L.Zhang, Processing of advanced materials using high-energy mechanical milling, Progress in Materials Science, 49, 2004, 537-560.

18. BC Kandpal, J Kumar and H Singh, Production Technologies of Metal Matrix Composite: A Review, International Journal of Research in Mechanical Engineering and Technology, 2014, 2(2), 27-32.

19. White, I Hughes, T Willis, R Jordan, Metal matrix Composites based upon Aluminium, lithium and Silicon carbide, HAL Journal de Physique Colloques, 1987, 48, C3, C3-347- C3-353.

20. Rodriguez-Reyes M, Pech-Canul I, Rendon-Angeles J and Lopez-Cuevas J, (2006), Composite Science Technology, 66, pp. 1056.

21. Sato Y S, Kokawa H, Enomoto M and Jogan S, (1999), Metall Mater Trans A, 57, pp. 2429-2437.

22. Jayaseelan V, Kalaichelvan K, Kannan M, Ananth SV. Extrusion Characterizes of $\mathrm{Al} / \mathrm{SiC}$ by different Manufacturing Process. Int J App Engine Res, Dindigul, 2010; 1: 1.

23. M. K. Surappa, J. Mater. Proc. Tech. 63 (1997) 325.

24. M. M. Schwartz, Composite materials, volume II: processing, fabrication and applications, Prentice Hall PTR, 1997.

25. J. Segurado, C. Gonzalez and J. Llorca: Acta Materialia 51, (2003), 2355

26. X. Deng and N. Chawla: J. Mater. Sci 41, (2006), 5731.

27. S. F. Corbin and D. S. Wilkinson: Acta Matell.Mater. 42, (1994), 1311.

28. A.J. Reeves, H. Dunlop and T. W. Clyne: Metall. Trans. 23, (1991), 970.

29. Sedat Ozden, Recep Ekici and Fehmi Nair, Composites: Part A 38 (2007) 484

30. Zhang Peng and Li Fuguo, Rare Metal Materials and Engineering 39 (2010) 1525 .

31. S. Balasivanandha prabhu, L. Karunamoorthy, S. Kathiresan and B. Mohan, Material Processing Technology 171 (2006) 268.

32. N. Hari Babu, S.Tzamtzis, N. Barekar, J. B. Patel and Z. Fan, Fabrication of Metal Matrix Composites under Intensive Shearing, Solid State Phenomena Vols. 141-143 (2008) pp 373-378.

33. S. Tzamtzis, N.S. Barekar, N. Hari Babu, J. Patel, B.K.Dhindaw and Z Fan, Composites: Part A 40 (2009) 144.

34. Z. Zhang and D. L. Chen: Scripta Materialia 54, (2006), 1321.

35. B.G. Park, A.G.Crosky and A.K.Hellier, Composites: Part B 39 (2008) 1270

36. M. Kok, Materials processing Technology 161 (2005) 381

37. Abhishek Kumar, Shyam Lal, Sudhir Kumar Noida, In: JMRTEC-40.

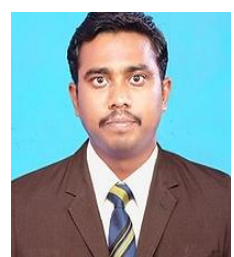

\section{AUTHORS PROFILE}

S. Suresh Kumar completed his Ph.D. degree in Mechanical Engineering from Kalasalingam Academy of Research and Education (KARE), India in 2016. He also completed Post-doc from Karadeniz Technical University, Turkey in 2018. Currently, he is doing his research in the area of non-traditional machining on metal matrix composites.

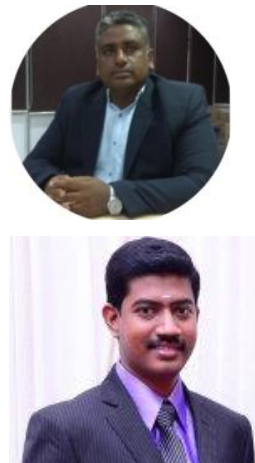

M. Uthayakumar completed his Doctoral work in the area of Precision Machining. He is actively working in the development of high strength light weight composites. His other areas of interest include processing of metal matrix, polymer matrix, ceramic matrix composite and its performance studies

S. Thirumalai Kumaran completed his $\mathrm{Ph} . \mathrm{D}$. degree in Mechanical Engineering from Kalasalingam Academy of Research and Education (KARE), India, in 2015. After completing Ph.D., he worked as an Assistant Professor at School of Mechanical Engineering, Yeungnam University, South Korea for a period of one year. He is currently an Associate Professor at School of Automotive and Mechanical Engineering, KARE.

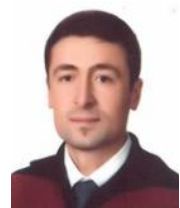

Temel varol completed his Ph.D in Materials and Metallurgical Engineering from Karadeniz Technical University, Trabzon, Turkey in 2017.

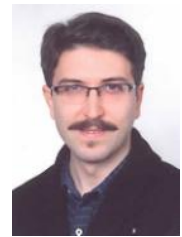

Fatih Erdemir completed his Ph.D in Materials and Metallurgical Engineering from Karadeniz Technical University, Trabzon, Turkey in 2017 